\title{
"Nós não compreendemos exatamente o que ela quis dizer com "vômito negro"”: Fundação Rockefeller, ciência e a epidemia de febre amarela de 1926
}

Ricardo dos Santos Batista

\section{RESUMO}

Este artigo analisa a incidência da febre amarela no Nordeste brasileiro no ano de 1926 e os seus desdobramentos científicos. Após a epidemia, foram realizadas inspeçôes em cidades nas quais ocorreram surtos, no intuito de refutar a existência da amarílica. Além disso, com o redirecionamento das atividades da Fundação Rockefeller, foi criado o laboratório da febre amarela, em Salvador, em 1928. Utilizam-se como fontes correspondências, relatórios e diários da Fundação Rockefeller e jornais brasileiros para compreender as especificidades da epidemia. O evento de 1926 foi de grande importância para o desenvolvimento da saúde internacional e influenciou estratégias e açóes no controle da amarílica.

Palavras-chave: Fundação Rockefeller; febre amarela; saúde internacional; teoria dos focos-chave; conhecimento científico.

\section{"We did not understand what just what she meant by 'black vomit": Rockefeller Foundation, science, and the 1926 yellow fever epidemic}

\section{ABSTRACT}

This article analyzes the outbreak of yellow fever in Northeastern Brazil in 1926 and its related scientific developments. After the epidemic, inspections were carried out in cities where outbreaks occurred and elsewhere in order to refute the existence of yellow fever. Additionally, the Rockefeller Foundation created a yellow fever laboratory in Salvador in

DOI: http://dx.doi.org/10.1590/2237-101X02204805

Artigo recebido em 31 de janeiro de 2021 e aceito para publicação em 30 de março de 2021.

Essa pesquisa foi realizada com o apoio do Conselho Nacional de Desenvolvimento Científico e Tecnológico - CNPq, processo 150410/2019-0, como parte do pós-doutorado realizado na Faculdade de Medicina Preventiva da USP, sob a supervisão do professor Dr. André Mota.

* Professor da Universidade do Estado da Bahia / Programa de Pós-Graduação em História - Campus II, Alagoinhas/BA - Brasil, Pós-doutorando na Faculdade de Medicina de São Paulo. E-mail: kadobatista@ hotmail.com. ORCID: https://orcid.org/0000-0002-7959-5929. 


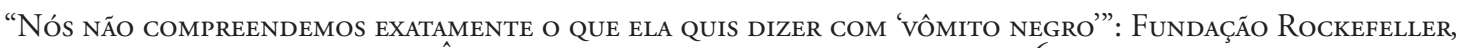
CIÊNCIA E A EPIDEMIA DE FEBRE AMARELA DE I 926

1928 as part of a redirection in its activities. This paper uses Brazilian newspapers as well as correspondence, reports, and diaries from the Rockefeller Foundation to understand the specificities of the 1926 epidemic, which was of great importance for the development of international health strategies and actions for controlling yellow fever.

Keywords: Rockefeller Foundation; yellow fever; international health; key focus theory; scientific knowledge.

\section{"Nosotros no comprendemos exactamente lo que ella quiso decir con "vómito negro"”: Fundación Rockefeller, ciencia y la pandemia de fiebre amarilla de 1926}

\section{RESUMEN}

Este artículo analiza la incidencia de la fiebre amarilla en el Noreste Brasileño en el año 1926 y sus despliegues científicos. Después de la pandemia, fueron realizadas inspecciones en ciudades en las cuales ocurrieron brotes, con la intención de refutar la existencia de la enfermedad. Además de ello, con el redireccionamiento de las actividades de la Fundación Rockefeller, fue creado el laboratorio de la fiebre amarilla, en Salvador, en 1928. Se utilizan como fuentes, correspondencias, relatos y diarios de la F undación Rockefeller y periódicos brasileńos para comprender las especificidades de la pandemia. El evento de 1926 fue de gran importancia para el desarrollo de la salud internacional e influyó en las estrategias y acciones en el control de la enfermedad.

Palabras Clave: Fundación Rockefeller; fiebre Amarilla; salud internacional; teoría de los focos-clave; conocimiento científico.

Em 24 de abril de 1925, o periódico soteropolitano $A$ Tarde publicou uma entrevista com J. H. White, responsável pela atuação da Fundação Rockefeller no Brasil. ${ }^{1} \mathrm{O}$ médico considerava a febre amarela erradicada nos estados do Norte, ${ }^{2}$ locais nos quais a agência filantrópica assumiu o controle da doença a partir de um acordo com o Departamento Nacional de Saúde Pública (DNSP) em 1923. White esperava que as turmas de mata-mosquitos da Rockefeller permanecessem até o final daquele ano nas cidades de Santo Amaro, Cachoeira, Nazaré, Santo Antônio de Jesus, São Félix e Castro Alves, todas localizadas no recôncavo da Bahia, mesmo que não houvesse mais vestígios da amarílica. Acreditava-se que nenhum caso a mais da doença ocorreria no continente americano, exceto se ela fosse trazida de algum

\footnotetext{
${ }^{1}$ A Fundação Rockefeller foi criada em 1913, como fruto da filantropia de John Dawson Rockefeller. A sua atuação na saúde internacional ocorreu por meio da International Health Comission, entre 1913 e 1916; que se tornou International Health Board e atuou entre 1916 e 1927; e que, por fim, passou a se chamar International Health Divison, de 1927 até seu fechamento em 1951 (cf. FARLEY, 2004, p. 2).

${ }^{2}$ Até a década de 1920, a regiấo Nordeste do Brasil ainda era conhecida como Norte do país.
} 


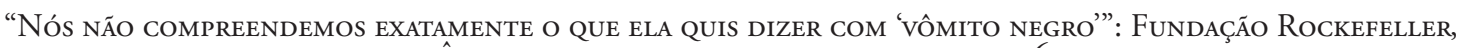
CIÊNCIA E A EPIDEMIA DE FEBRE AMARELA DE I926

lugar do exterior, como, por exemplo, a Costa da África, onde ainda existia ${ }^{3}$.

A incidência relatada de febre amarela declinou tanto que a agência internacional fechou postos de controle da enfermidade nos estados do Norte, exceto em quatro deles (CUETO, 1995, p. 230). Esse fato ampliava a credibilidade atribuída à teoria dos focos-chave, que orientava o controle da doença não só no Brasil, mas no Peru, Colômbia, México, entre outros países americanos, e também pretendia guiar os trabalhos na África. A teoria propunha que era viável acabar com a amarílica eliminando-se os locais onde o mosquito Aedes aegypti, considerado seu único vetor, se proliferava. As campanhas deveriam ser realizadas nos grandes centros populosos, nos quais bastaria reduzir o índice de infestação a um patamar igual ou inferior a cinco por cento para obter o sucesso almejado (BENCHIMOL, 2001, p. 113-114).

Não se imaginava, no entanto, que essas concepçôes começariam a ser abaladas por uma epidemia que se manifestou com intensidade no primeiro semestre de 1926. A confirmação da doença, que atingiu pequenas cidades do interior do Norte, levantou os primeiros questionamentos sobre a eficácia da teoria dos focos-chave: um evento local que implicou sobre a atuação da agência filantrópica em escala global. As dúvidas se aprofundaram e evidenciaram os equívocos da teoria quando, em 1928, ocorreu uma outra epidemia, no Rio de Janeiro. Segundo John Farley:

A confiança inicial do International Health Board na teoria também estava começando a se desgastar. Connor especulou que poderia haver falhas na teoria dos focos-chave quando, em 1926, surtos ocorreram em cidades do interior ao longo do Vale do Rio São Francisco e em Juazeiro no estado do Ceará [...] Mesmo assim, ele defendeu a teoria, argumentando que revolucionários não-imunes e tropas federais do Sul passaram por essas áreas entre 1925 e 1926 e podem ter sido transportadas (FARLEY, 2004, p. 100). ${ }^{4}$

Este texto tem como objetivo analisar a epidemia de febre amarela que ocorreu no Brasil, em 1926, e seus desdobramentos em anos seguintes, considerando-os capítulos importantes para o desenvolvimento da saúde internacional, especialmente no que diz respeito às medidas de controle sobre a febre amarela nas Américas. Anne-Emanuelle Birn (2006, p. 4-5) afirma que a noção de "saúde internacional" surgiu na interseção da internacionalizaçấo econômica e científica e envolveu, ao mesmo tempo, o local, o nacional e os interesses públicos e privados. Isso ocorreu em um contexto de imigraçáo em larga escala dos europeus para

\footnotetext{
${ }^{3}$ A FEBRE amarella está extincta: declarações sensacionais do dr. White, chefe da Missão Rockefeller no Brasil. A Tarde, Salvador, 24 abr. 1925, p. 1.

${ }^{4}$ No original: "The Health Board's early confidence in the theory was also beginning to erode. Connor speculated that there might be flaws in the seedbed theory when, in 1926, outbreacks apread to interior towns along the San Francisco River Valley and to Juazeiro Ceara State [...] Neverthelless, he held to the theory, arguing that nonimmune revolutionaries and federal troops from the south had passed through these areas in 1925 and 1926 and might have been carriers" (tradução do autor).
} 


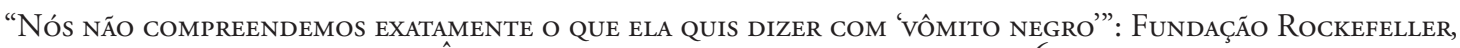
CIÊNCIA E A EPIDEMIA DE FEBRE AMARELA DE I 926

vários países e da explosão do capitalismo industrial e do comércio, o que aumentou a ameaça de doenças epidêmicas em todo o mundo. Dessa forma, surtos de peste, febre amarela, cólera e outras doenças não eram mais motivo de preocupação local, disputas binárias ou gerentes coloniais. Há muito tempo, as potências imperiais prestavam atenção no papel da saúde pública na proteção dos exércitos colonizadores. $\mathrm{O}$ crescimento da interdependência econômica aumentou os perigos potenciais da doença e tornou o seu controle um assunto político muito mais complicado, envolvendo ambientes dentro e além das estruturas imperiais existentes (BIRN, 2006, p. 5).

Direcionar o olhar, também, para o momento posterior à manifestação epidêmica auxilia na compreensão sobre como certos episódios impactaram em práticas científicas por um período mais duradouro. As marcas que uma epidemia deixa na sociedade, seja nos costumes, nas instituiçôes ou mesmo nas ciências podem ser observadas após o seu arrefecimento. No caso analisado, os membros do staff da Fundação Rockefeller, especialmente Michael Connor ${ }^{5}$, fizeram viagens para tentar comprovar que as febres que grassavam nas cidades do interior não eram causadas pela amarílica, em 1927. E, em 1928, a criação de um laboratório da febre amarela, na cidade de Salvador, contribuiu para conectar o conhecimento científico do Brasil e da África e implicou novas estratégias para tentar erradicá-la. O argumento defendido aqui é o de que a epidemia de 1926 desempenhou um papel central no desenvolvimento da saúde internacional, para a elaboração de estratégias e açôes de controle da doença executadas por instituiçôes e agentes brasileiros e norte-americanos, em um período posterior à sua incidência.

A febre amarela nas Américas é um tema consolidado na historiografia da saúde (CUETO, 1995; BENCHIMOL, 2001; FARLEY, 2004; BIRN, 2006; LÖWY, 2006; BENCHIMOL et al, 2009; MAGALHÃES, 2016; BATISTA; SOUZA, 2020; PORTO, 2020a). Alguns dos autores que analisam a enfermidade, em perspectiva histórica, a exemplo de Farley (2004, p. 100), mencionam a importância da epidemia de 1926 para o questionamento da teoria defendida pelos membros da agência filantrópica internacional, mas ainda há reflexóes a serem realizadas sobre esse episódio.

Eventos epidêmicos são fenômenos biológicos, mas também sociais, que promovem transformaçôes nas sociedades nas quais incidem. Segundo Charles Rosenberg (1989), para que uma epidemia seja reconhecida como tal, é necessário que haja uma dimensão episódica. A doença precisa ocorrer como um evento, o que impóe uma resposta imediata e ampla. A partir disso, problematiza-se: como os agentes de ciência se comportaram em meio a uma epidemia que questionou conhecimentos válidos de forma global? Quais as açôes e os conflitos provenientes de um "ressurgimento" da febre amarela no continente americano e da atuação da Fundação Rockefeller?

\footnotetext{
${ }^{5}$ Michael Connor nasceu em Massachusetts e se formou na Dartmouth Medical School. Ele serviu o Corpo Médico do Exército dos Estados Unidos nas Filipinas e, ao entrar para o International Health Board, atuou como inspetor sanitário chefe adjunto no Projeto do Canal do Panamá (FARLEY, 2004, p. 92).
} 
“Nós NÃo COMPREENDEMOS EXATAMENTE O QUE ELA QUiS DIZER COM 'VÔMITO NEGRO’”: FUNDAÇÃo RoCKEFELLER, CIÊNCIA E A EPIDEMIA DE FEBRE AMARELA DE I 926

Ricardo dos Santos Batista

Para a elaboração deste artigo, foram utilizados como fontes relatórios, diários e correspondências, produzidos pela agência filantrópica, e periódicos de diferentes lugares do Norte, que auxiliam a compreender particularidades do processo epidêmico.

\section{A febre amarela em 1926 no Brasil}

Ainda no mês de janeiro de 1926, antes que as autoridades médicas e políticas imaginassem que o Norte brasileiro atravessaria uma epidemia de febre amarela, alguns casos já haviam sido relatados sobre uma "epidemia que surgiu na área de Santa Cruz, em Pernambuco", próximo à fronteira com a Paraíba, ao longo dos meses de outubro a dezembro de $1925^{6}$. Os relatórios produzidos pelos médicos enviados para investigar a enfermidade eram inconclusivos, visto que não indicavam qual doença reinava naquele lugar. Um deles afirmou que não sabia o que era, mas que não pensava ser febre amarela e o segundo afirmou que as evidências indicavam um diagnóstico de praga septicêmica.

Naquele momento, a crença no sucesso da campanha de erradicação da febre amarela era táo grande que a imprensa recifense ainda reproduzia inúmeros elogios à atuação da agência filantrópica no Ceará. A característica a que se atribuía maior valor era, sem dúvida, a eliminação dos mosquitos: "Hoje, porém, depois da tenacíssima campanha movida pelo gênio humanitário de Rockefeller, Fortaleza está expurgada de tão incômodos animaizinhos e isso constatamos com satisfação" .

Contudo, os relatórios recebidos nos primeiros meses de 1926, vindos do Vale do São Francisco, da Paraíba e de Natal, informavam à agência internacional sobre um possível reaparecimento da amarílica, especialmente em pequenas cidades do interior. Isso despertou o interesse dos membros do seu staff em diagnosticar se a entidade específica que causava o adoecimento de pessoas era a febre amarela, identificando-a por meio de sintomatologia e de análise clínica. A esse respeito, Charles Rosenberg (2002) discute a importância do diagnóstico para a medicina, que se tornou cada vez mais técnica, especializada e burocratizada ao longo dos séculos XIX e XX. A percepção da doença enquanto uma entidade específica - o que exigia, por exemplo, um vocabulário próprio que a definisse e a diferenciasse de outras manifestaçóes - pôde ser elaborada a partir do diagnóstico, do prognóstico e da racionalização da prática terapêutica, que se relacionaram, cada vez mais, a categorias específicas e acordadas da doença, tanto no conceito quanto na prática cotidiana. E, mesmo o fato de doenças epidêmicas como a febre amarela já serem admitidas como contagiosas ao longo do século XIX, não impediu que membros da Fundação Rockefeller tentassem elaborar diagnósticos

\footnotetext{
${ }^{6}$ SCANNELL, E. J. Summary of yellow fever situation in Brazil Jan. to Aug., 1926 by E. J. Scannell. RAC, RF records, IHB, Division records, RG 5, Series 3, FA 115, Box 114, Folder 1454. 5 ago. 1926.

${ }^{7}$ ACÇÃO DA Fundação Rockefeller no Ceará. Diário de Pernambuco, Recife, 13 mar. 1926, p. 1.
} 


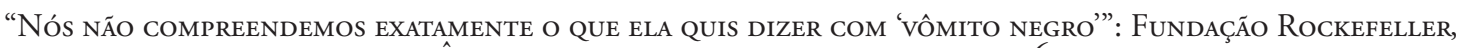
CIÊNCIA E A EPIDEMIA DE FEBRE AMARELA DE I 926

negativos da amarílica, após a epidemia de 1926, como forma de manter a vigência da teoria dos focos-chave.

Em consonância com a teoria, o argumento utilizado pelo IHB para tentar justificar a presença da febre amarela de modo epidêmico era que, embora a maioria das cidades interioranas, quando consideradas como unidades populacionais individuais, fossem pequenas demais para figurarem como centros endêmicos, um grupo dessas comunidades poderia se constituir como uma área única para formar um centro endêmico se tivesse comunicação fácil e frequente. Uma dessas áreas, desconhecidas até a primavera de 1926, foi encontrada na parte sudeste do estado do Ceará, onde cidades do Juazeiro (do Norte), Crato, Barbalho e Missão Velha continham um agregado de 50.000 pessoas $^{8}$. A defesa de que pequenas cidades poderiam formar um centro endêmico era uma forma de tentar manter a validade da teoria dos focos-chave, adequando-a àquela realidade.

A estação de controle da febre-amarela em Recife recebeu notícias da doença no município de Logradouro, no estado de Pernambuco. A cidade estava localizada a 6 horas da ferrovia, a noroeste de Caruaru. Embora o principal surto na cidade da Paraíba (João Pessoa) não tivesse ocorrido até abril, a enfermidade foi detectada pelas autoridades locais em janeiro de 1926 ou em dezembro do ano anterior. Já no estado do Ceará, a história de um surto em Juazeiro (do Norte) foi investigada em março e, nessa época, foram descobertas características possivelmente endêmicas na região.

No que diz respeito ao estado da Bahia, as primeiras informaçóes foram recebidas em Salvador, vindas de Xique-xique, na região do Rio São Francisco, no início de março de 1926. Naquele estado, a presença da febre amarela não era considerada definitivamente aparente até cerca de $1^{\circ}$ de abril. Foi nesse mês que João Pessoa teve um surto de amarílica e, ao mesmo tempo, diagnosticou-se a febre no interior do Rio Grande do Norte, da Paraíba e da Bahia9. Segundo Azemar Soares Júnior (2020, p. 402), a doença grassou de forma violenta em várias cidades do estado paraibano, especialmente na cidade da Paraíba, e com menor força nos municípios de Campina Grande, Itabaiana, Cabedelo, Santa Rita, Guarabira, Bannaneiras e Alagoa Grande, e a Fundação Rockefeller estabeleceu os trabalhos de combate ao stegomyia calopus com possível brevidade. ${ }^{10}$

Em 10 de julho, a população das cidades localizadas ao longo dos trilhos da linha férrea que ligava Salvador a Juazeiro (da Bahia, cidade também localizada no Vale do Rio São Francisco) demonstravam preocupação com a disseminação de doenças:

Informações ha pouco chegadas no interior do Estado trazem a nova alarmante de terrem irrompido nos municípios de Santa Luzia e Queimadas, perto de Coité surtos epidêmicos de

\footnotetext{
${ }^{8}$ ROCKEFELLER Foundation. RAC. Report of yellow fever outbreak Brazil, 1926. RF records, IHB, Division records, RG 5, Series 3, FA 115, Box 114, Folder 1454. 26 ago. 1926.

${ }^{9}$ Ibidem, p. 4.

${ }^{10}$ Stegomyia era como se conhecia a família do mosquito Aedes aegypti (Stegomia fasciata).
} 
“Nós NÃo COMPREENDEMOS EXATAMENTE O QUE ELA QUIS DIZER COM 'VÔMITO NEGRO””: FUNDAÇÃo RocKEFELLER, CIÊNCIA E A EPIDEMIA DE FEBRE AMARELA DE 1926

Ricardo dos Santos Batista

varíola e febres que se suppóe ser amarella, ao mesmo tempo, estando as respectivas populaçóes bastante sobressaltadas ${ }^{11}$.

Aos poucos era impossível negar que um grande surto de febre amarela assolava o Norte (Figura 1). Uma viagem realizada por Francisco Freire de Carvalho, ${ }^{12}$ na companhia de Carlos Burle de Figueiredo, chefe do Instituto Oswaldo Cruz da Bahia (IOC-Ba), auxiliou na confirmação da incidência da doença em diferentes cidades. A investigação ocorreu em Carrapichel, Corniba, Tanquinho de Miguel Calmon, França, Alagoinhas, Petrolina e Jacobina, todas no norte da Bahia. A partir da análise de casos clínicos e de conversas com médicos locais, eles chegaram à conclusão que: a epidemia reinante no interior era a febre amarela; a febre amarela existiu no interior desde aproximadamente dezembro de $1925 \mathrm{ou}$ janeiro de 1926; a epidemia não foi diagnosticada com precisão em seu início; o que foi chamado de febre tifoide ou malária era, na verdade, febre amarela; e, por fim, que o número de casos fatais chegou a várias centenas de pessoas ${ }^{13}$.

Figura 1: Áreas que relataram febre amarela em 1926 no Brasil

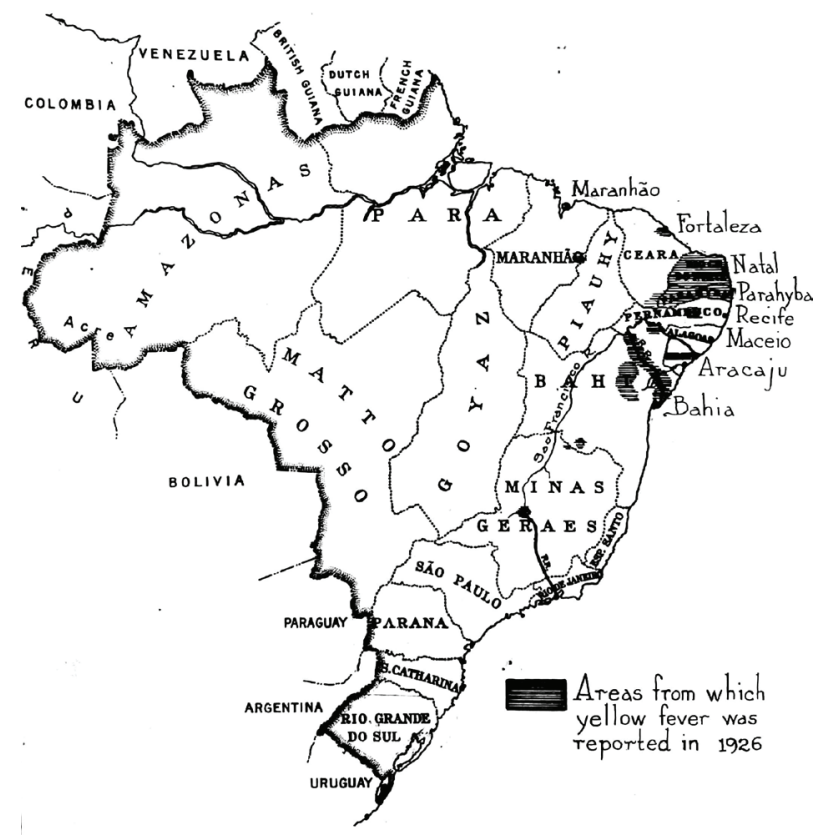

Fonte: RAC, RF records, IHB, Division records, RG 5, Series 3, FA 115, Box 114, Folder 1454

\footnotetext{
${ }^{11}$ A RONDA dos epidêmicos. A Tarde, Salvador, 10 de jul. 1926, p. 1.

${ }^{12}$ Francisco Freire de Carvalho se graduou na Faculdade de Medicina da Bahia, em 1914, e trabalhou para a Fundação Rockefeller a partir de 1923.

${ }^{13}$ FREIRE para Carr (correspondência). RAC, RF records, IHB, Division records, RG 5, Series 3, FA 115, Box 127, Folder 1522. 10 abr. 1926.
} 


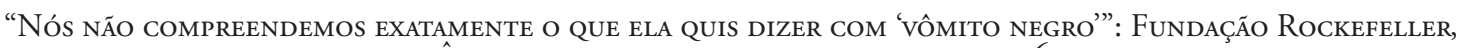
CIÊNCIA E A EPIDEMIA DE FEBRE AMARELA DE I 926

Em maio de 1926, o governo de Belém, no Pará, tomava "medidas enérgicas" para tentar evitar a irrupção da amarílica ${ }^{14}$. Enquanto isso, o periódico soteropolitano Diário de Notícias, que fazia oposição ao governador Francisco Marques de Góes Calmon (1924-1928) e ao seu genro, subsecretário de Saúde e Assistência Pública, Antônio Luis Cavalcanti de Albuquerque de Barros Barreto, que foi bolsista da Fundação Rockefeller e era Inspetor do DNSP (BATISTA, 2019b; BATISTA, 2020; BATISTA; SILVA, 2020), reproduziu a carta de um dentista de Alagoinhas, que fazia uma verdadeira "súplica" pela intervençâo do periódico junto ao Governo e à Saúde Pública, para que fossem enviados mata-mosquitos e material para a profilaxia da febre amarela naquela cidade ${ }^{15}$.

Se a questáo científica acompanhava as açôes da Fundação Rockefeller e impactava especialmente na vida da populaçáo pobre, que sofria intervençôes dos mata-mosquitos em suas residências, ela também se fez presente em, pelo menos, outras duas frentes. A primeira delas diz respeito ao papel dos líderes políticos e sanitários brasileiros em tempos epidêmicos. A incidência da doença pode ter sido importante para o estabelecimento de conexóes em nível internacional, com acordos que visavam controlar epidemias em diferentes naçôes. Enquanto a febre amarela incidia sobre o Norte, Carlos Chagas participou da reunião do Comitê de Higiene da Liga das Naçôes, na França. Como representante do Brasil, apresentou um relatório e criou-se um Comitê de estudos, com sede em Lima, no Peru, para o qual foi escolhido como presidente. A Conferência Sanitária Internacional lhe atribuiu a responsabilidade de escrever um relatório sobre a febre amarela, que serviria de base para o novo Código Internacional de Higiene ${ }^{16}$. Esse fato é um exemplo de como a presença da amarílica era uma preocupação ampla, que atingia diferentes níveis de organização para a sua erradicação, inclusive em nível internacional.

Em uma outra perspectiva, a ciência alcançava a vida das pessoas, especialmente através das informaçôes direcionadas às elites letradas sobre o comportamento da doença. Um exemplo foi a divulgação de propagandas de insumos para acabar com larvas amarílicas. Ao longo de 1926, o Diário de Pernambuco reproduziu a propaganda de Cruzwaldina (Figura 2). Nela, afirmava-se estar "cientificamente comprovado" que o único transmissor do "Leptospira Ichteroides (micróbio descoberto pelo bacteriologista japonês Hideyo Noguchi)" era o mosquito conhecido no Norte brasileiro como "muriçoca ou carapaná, também chamado de stegomyia calopus".

\footnotetext{
${ }^{14}$ CONTRA A febre amarella. Diário de Pernambuco, Recife, 29 maio 1926, p. 1.

${ }^{15}$ TEREMOS FEBRE amarela em Alagoinhas? A Tarde, Salvador, 4 maio 1926, p. 1.

${ }^{16}$ COMITÉ DE Hygiene da Liga das Naçóes. Diário de Pernambuco, Recife, 29 maio 1926, p. 1.
} 
“Nós NẤ COMPREENDEMOS EXATAMENTE O QUE ELA QUIS DiZER COM 'VÔMITO NEGRO””: FUNDAÇÃo RoCKEFELLER, CIÊNCIA E A EPIDEMIA DE FEBRE AMARELA DE 1926

Figura 2: Propaganda de Cruzwaldina

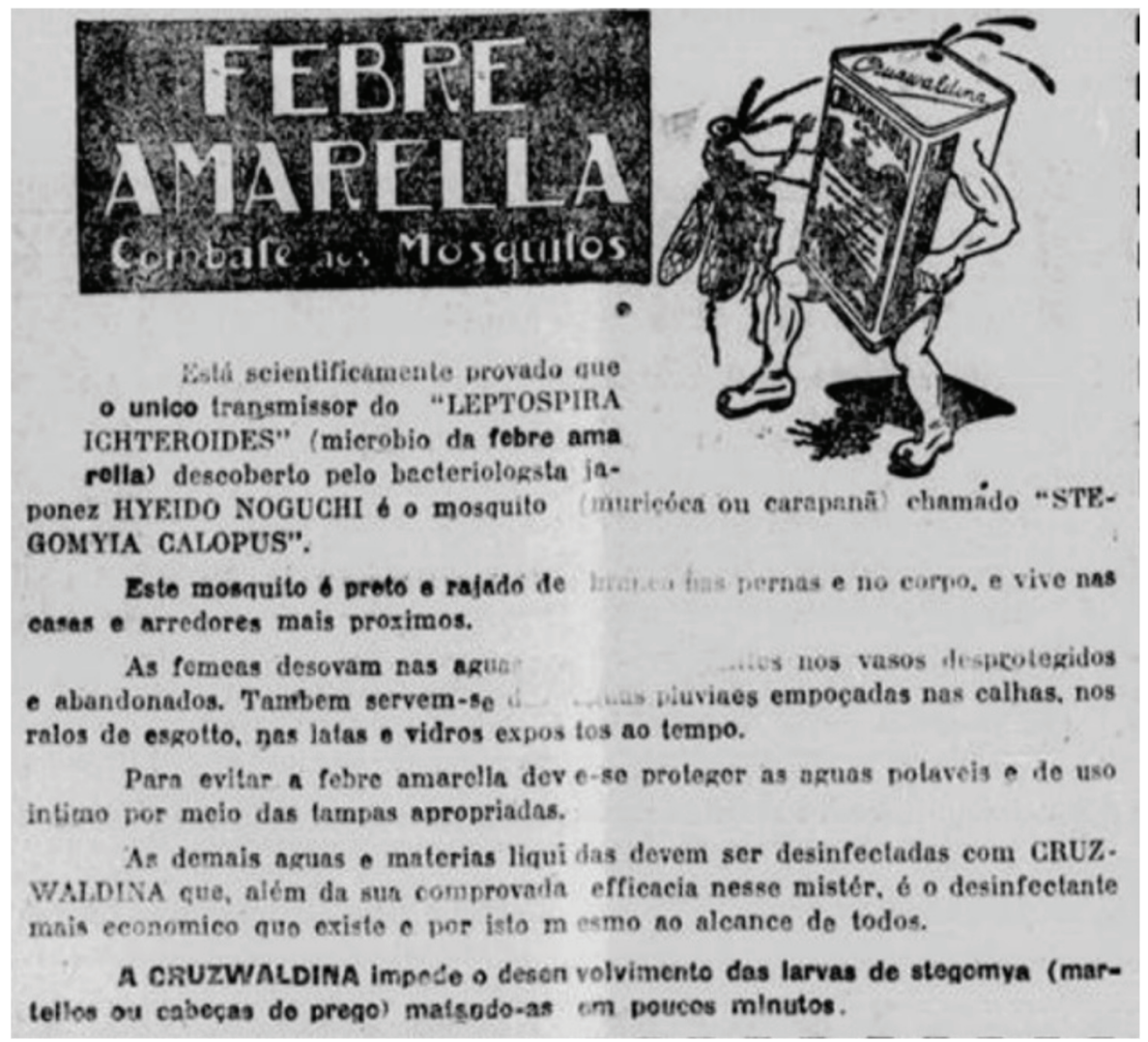

Fonte: Diário de Pernambuco, 10 jul. 1926, p. 7

Noguchi era um cientista que trabalhava para a Fundação Rockefeller e, assim como anunciado por Cruzwaldina, considerava ter encontrado o agente causador da enfermidade (BENCHIMOL et al, 2010). É importante ressaltar que, naquele momento de epidemia, a propaganda associava o conhecimento científico vigente ao produto divulgado, como estratégia para ampliar as vendas. Essa náo era a primeira vez que produtos eram vendidos, em tempos epidêmicos, com a apropriação de um discurso científico no Brasil. Segundo Liane Bertucci (2004, p. 173), desde os primeiros dias da epidemia de influenza de 1918, muitos medicamentos foram apresentados à população de São Paulo como capazes de aliviar os transtornos causados pela enfermidade, impedir seu aparecimento e reestabelecer o vigor aos sobreviventes. Comerciantes de remédios, por exemplo, inundaram as páginas dos jornais com suas propagandas, "respaldados no discurso médico sobre os possíveis e limitados efeitos de algumas substâncias (como quinino) e preparados, que poderiam ajudar no trato dos gripados e até concorrer para a não manifestação da moléstia”.

As informações científicas presentes na propaganda não se limitaram à descrição do achado de Noguchi. Afirmava-se, ainda, que o mosquito era "preto com rajado de branco nas pernas e no corpo" e vivia em casas e arredores mais próximos. Foram apresentados 


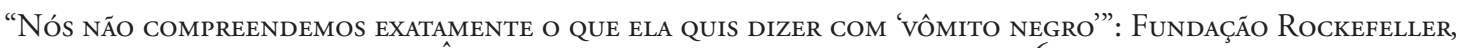
CIÊNCIA E A EPIDEMIA DE FEBRE AMARELA DE I 926

detalhes sobre os lugares de desova das fêmeas e alertou-se sobre o perigo de sua proliferação em água empoçada em calhas e ralos de esgoto. Recomendava-se que a água potável fosse protegida com tampas adequadas e, em todas as outras, poder-se-ia aplicar Cruzwaldina.

O nome do composto era inspirado em Oswaldo Cruz, médico que se destacou pela erradicação da febre amarela no Rio de Janeiro, em 1909. Contudo, a utilização de óleo em reservatórios de água se alinhava muito mais às práticas da Fundação Rockefeller do que às de Oswaldo Cruz, que investiu, essencialmente, em um processo de fumigação das casas para acabar com os mosquitos (FARLEY, 2004, p. 96). Steve Williams (1994) analisa os conflitos entre brasileiros e norte-americanos em relação ao uso da fumigação e aponta os argumentos contrários à sua utilização, identificados pela Fundaçáo Rockefeller, a exemplo: do alto custo daquele método; de sua baixa eficácia, visto que após algum tempo os mosquitos ocupavam os mesmos locais; e de um receio encontrado por autoridades sanitárias brasileiras para romper com práticas ortodoxas, o que poderia colocar em risco sua possível ascensão na carreira (WILLIAMS, 1994, p. 29).

Os métodos da agência filantrópica internacional causaram conflitos com a população brasileira, porque os guardas mata-mosquitos utilizavam óleo nos recipientes de água potável e entravam em estabelecimentos privados em horários impróprios. Em 23 de julho de 1926, por exemplo, o médico Archimedes Marques, Chefe do Posto de Saneamento Rural de Nazareth, na Bahia, escreveu para o Subsecretário de Saúde e Assistência Pública e informou que os representantes da Comissão Rockefeller se excediam no serviço de polícia de focos, o que resultava em constantes atritos e reclamaçóes de todas as camadas sociais e fazia com que ele fosse requisitado, constantemente, para resolver conflitos que lhes traziam "contrariedades e prejuízo de tempo"17.

Em outras propagandas, a relação entre a concepção do produto e os métodos utilizados pelos norte-americanos ficava mais explícita. No mês de setembro, o anúncio de um outro óleo alertou os leitores recifenses para a importância dos "homens da ciência" que perdiam suas vidas no estudo das "febres mortíferas". Por isso, a mundial Standard Oil, em Nova Jersey, teria desenvolvido um meio infalível para destruir os transmissores da amarílica. A imagem utilizada na propaganda era a de um médico que atendia uma criança doente e, ao mesmo tempo, conseguia expulsar grandes mosquitos pela janela (Figura 3).

\footnotetext{
${ }^{17}$ MARQUES para Barros Barreto (correspondência). RAC, RF records, RG 5, Series 3, Subséries 3_305, FA 115, Box 127, Folder 1522. 23 jul. 1926.
} 
“Nós NÂO COMPREENDEMOS EXATAMENTE O QUE ELA QUIS DIZER COM 'VÔMITO NEGRO””: FUNDAÇÃo ROCKEFELLER, CIÊNCIA E A EPIDEMIA DE FEBRE AMARELA DE I 926

Figura 3: Propaganda de FLIT

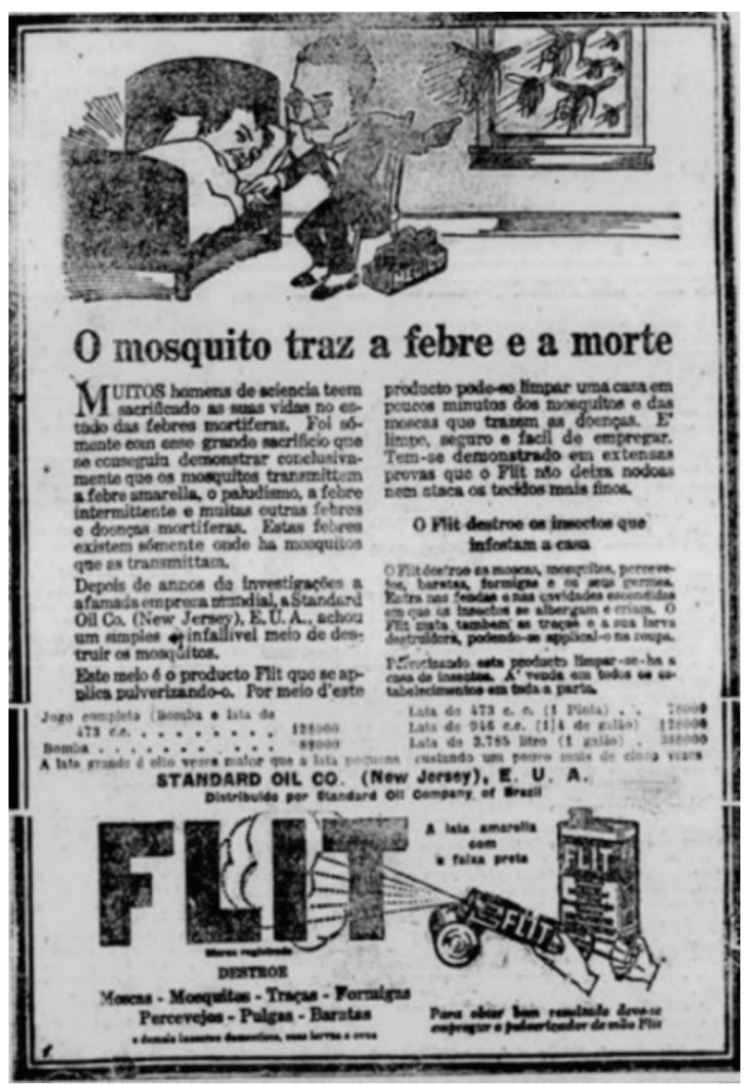

Fonte: Diário de Pernambuco, 15 set. 1926, p. 7

A Standard Oil, divulgada como responsável pelo estudo que validou a eficácia de FLIT era propriedade da família Rockefeller. Segundo Farley (2004, p. 2), ela foi fundada ainda em 1870 e dominou os mercados mundiais de petróleo com o controle de poços, do refino e do transporte da matéria-prima. Ao tratar da epidemia de febre amarela no Rio de Janeiro, Benchimol (2001, p. 123) afirma que o FLIT passou a ser divulgado em jornais e revistas da época, tornando-se um produto popular no Brasil, e que não há como comprovar a disposição da Fundação Rockefeller em promover o óleo da Standard Oil. Contudo, é preciso observar que a propaganda já se fez presente no Brasil durante a epidemia de 1926, e que não haver uma promoção explícita por parte da agência filantrópica não anula a existência de interesses do grupo familiar.

Nos anos que sucederam a epidemia, os membros do IHB desenvolveram estratégias e açôes influenciadas por aquele evento, com a direção de uma outra personagem. A Campanha Mundial de Erradicação da febre amarela da Rockefeller havia sido lançada em Guayaquil, no Equador, em 1918. O médico Michael Connor conseguiu eliminar o mosquito seis meses após o início dos trabalhos e, por 17 anos, nenhum caso foi relatado naquele 


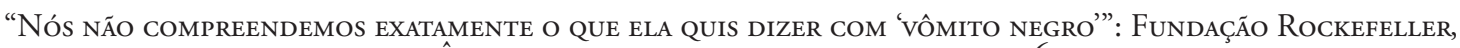
CIÊNCIA E A EPIDEMIA DE FEBRE AMARELA DE I 926

país. O modelo dos focos-chave foi norteador das suas açôes, além da utilização de peixes larvófagos em recipientes que armazenavam água (BENCHIMOL, 2001, p. 115; FARLEY, 2004, p. 92; MAGALHÃES, 2016, p. 61-62).

Connor também foi responsável por uma campanha em Vera Cruz, no México, entre 1920 e 1922, que eliminou a febre amarela do país. Com esse histórico de eficiência no controle da amarílica, ele foi convocado a assumir os trabalhos no Brasil, substituindo White. Convencido do sucesso da campanha, junto com outros especialistas norte-americanos, acreditava que a febre amarela já podia ser declarada extinta do país e do continente (MAGALHÂES, 2016, p. 74). Contudo, os relatórios sobre a epidemia no interior do Norte já haviam mostrado que ela não seria facilmente erradicada.

Em defesa do seu próprio trabalho, em outros lugares pelos quais passou, e da sua crença nos pressupostos científicos vigentes até então, Connor trabalhou para desfazer a imagem que a epidemia de 1926 havia suscitado. Ele se envolveu, inclusive, em uma controvérsia médica na Paraíba, com o doutor Guedes Pereira. Enquanto o médico local fez diagnósticos positivos sobre a doença, com auxílio de outros médicos paraibanos, o agente da Rockefeller tentava rechaçá-los no denominado "caso Jacaraú” (PORTO, 2020a).

Segundo Rosenberg (2002), a elaboração de diagnósticos legitimava a autoridade dos médicos e do sistema médico, facilitando decisóes clínicas particulares e fornecendo significados culturalmente acordados para a experiência individual. Ao serem codificadas em sistemas de classificação formal, as entidades de doença se tornavam ferramentas úteis, à medida que essas instituiçôes promissoras buscavam, ao mesmo tempo, impor uma ordem interna racional e projetar uma imagem de eficácia e ciência. Mais do que isso, as disputas em torno do diagnóstico de uma possível epidemia de febre amarela no Norte do Brasil implicavam interesses políticos, econômicos e sociais, e manutenção do prestígio de Connor em uma instituição que atuava em escala internacional.

Se constatasse (ou diagnosticasse) que os casos do Norte não eram de febre amarela, reificaria a atualidade da Rockefeller, guiada pelos conhecimentos mais aceitos sobre os meios de erradicar a doença: a teoria dos focos-chave. No entanto, o evento epidêmico e as evidências deixadas por ele teriam muito mais força do que as convicçóes daquele médico: validou os diagnósticos realizados pelos profissionais a quem ele se contrapôs, fortalecendo o campo científico brasileiro.

\section{Michael Connor e as febres do interior nordestino}

Ao longo de 1927, outras expediçóes foram realizadas em busca dos casos de febre amarela, mas nem sempre os investigadores chegaram à conclusão de que as febres que grassavam no interior eram manifestaçôes daquela enfermidade. Em 5 de janeiro, por exemplo, 


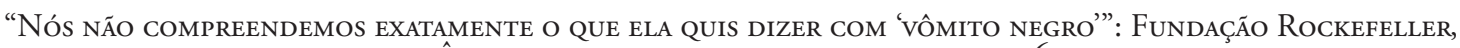
CIÊNCIA E A EPIDEMIA DE FEBRE AMARELA DE I 926

Michael Connor e J. Austin Kerr saíram de Salvador, no barco Rio Cachoeira, para Santo Amaro. Fizeram paradas na vila Madre de Deus, um pequeno povoado composto por aproximadamente 75 casas, em Bom Jesus, outra pequena vila, São Francisco e, por fim, na região chamada de Conde. Ao descerem da embarcação, seguiram em carros puxados por mulas por cerca de uma milha, em uma estrada que atravessava o manguezal. Eles foram recebidos por Taciano de Britto, chefe do posto de Profilaxia Rural da regiáo. O médico já havia feito uma inspeção em São Francisco do Conde, semanas antes, orientado por Barros Barreto, e coletou informaçôes de que a febre amarela esteve por ali. ${ }^{18}$

No dia seguinte, os três profissionais seguiram para São Francisco e convocaram o médico Sabino Fiuza, que presenciou a morte de uma criança da família "Tanajura" em 23 de outubro de 1926. Fiuza considerava que ela poderia ter morrido de amarílica, mas não afirmava com certeza, pois se afastou do atendimento no momento em que seus dois filhos também teriam adoecido. Quando voltou a atender a criança, Fiuza notou que ela gritava com dores na cabeça e no pescoço, o que poderia indicar algum tipo de meningite. Por fim, registrou a morte como febre tifo. Outro médico que auxiliou esse caso nos primeiros dias, Joáo Batista Tourinho, pensou que a enfermidade fosse malária ou febre tifoide, mas nunca febre amarela, que alegava ter visto por vários anos na cidade de Salvador. Nesse caso, observa-se a incapacidade de diagnosticar o agente específico que causava aqueles sintomas entre os moradores de São Francisco.

A inspeção em outros lugares da cidade, como, por exemplo, no Convento dos Franciscanos, mostrou a criação de stegomyia, mesmo que nenhum dos frades tenha adquirido a amarílica. Ao visitar casas para inspecionar os conteiners armazenadores de água, novas larvas foram identificadas. Uma senhora, proprietária da pensão onde almoçaram, disse que nenhum caso de febre amarela havia ocorrido lá, mas que, naquele ano, houve casos de 'vômitos negros' e citou, como exemplo, a criança "Tanajura". ${ }^{19}$

Em contraposição à possibilidade de que os vômitos fossem causados pela febre amarela, Connor afirmou: "Nós não compreendemos exatamente o que ela quis dizer com 'vômito negro'. Duvido muito que a criança Tanajura tenha morrido de febre amarela”. ${ }^{20}$ É interessante como Connor parecia não reconhecer um dos principais sintomas dos pacientes que adquiriam a febre amarela. Mesmo com a epidemia de 1926, e com as evidências de que a doença não havia sido completamente erradicada do Norte, ele hesitava em realizar um diagnóstico positivo e defendia a manutenção da teoria dos focos-chave pelo IHB.

${ }^{18}$ CONNOR, Michael Edward. Diary of the Yellow Fever Comission of Brazil by Dr. M. E. Connor, 1927. RAC, RF records, IHB, Division records, RG 5, Series 3, Subseries 3_305, FA 115, Box 127, Folder 1522, 1927, p. 5.

${ }^{19}$ Ibidem, p. 25.

${ }^{20}$ Idem. No original: "We could not obtain just what she mean't by 'Black vomit'. I doubt muchly that the Tanajura child died of yellow fever" (tradução do autor). 


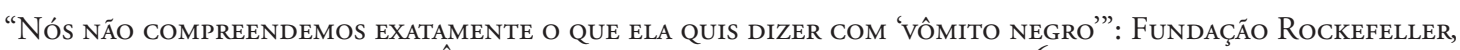
CIÊNCIA E A EPIDEMIA DE FEBRE AMARELA DE I 926

Ao mesmo tempo em que se posicionava contrário à existência da amarílica em casos clínicos, Connor tomava medidas importantes para o seu controle nas cidades do Norte. Uma reordenação de pessoal, realizada em setembro de 1927, por exemplo, indica como os agentes internacionais eram utilizados como verdadeiras peças em um tabuleiro de xadrez, movimentadas cuidadosamente com o intuito de erradicar a amarílica: H. A. Henry foi transferido de Salvador para Fortaleza, A. W. Burke de Recife para a Bahia, Lucien Smith de Fortaleza para a Paraíba (ou para viagens), J. Austin Kerr para a Paraíba (para a estação local ou para viagens), Mario Bião para Natal, no Rio Grande do Norte, e se pensava em dispensar, em breve, os serviços de Arthur Sainza. Michael Connor se propôs a assumir a estação de controle da febre amarela em Recife e, quando fosse necessário, a deixaria sob a supervisão direta de Gouveia de Barros, Chefe da Profilaxia Rural. ${ }^{21}$

O trabalho realizado por Connor incluía a supervisão das açóes de controle da amarílica, desenvolvidas pelos membros do staff da Rockefeller. Ao chegar em cada estado, ele articulava conversas com os chefes da Profilaxia Rural, visitava bairros e casas em que havia suspeita de febre amarela, orientava sobre a limpeza de valas públicas, coleta de latas nos lixões das grandes cidades e sobre a utilização de óleo para pulverização de locais não alcançados pelos guardas mata-mosquito. O médico buscava informaçôes sobre a história da febre amarela nos diferentes lugares por onde passava, na tentativa de descobrir se a enfermidade era ou não endêmica. ${ }^{22}$

É preciso destacar que a relação entre membros da Fundação Rockefeller e as autoridades locais era marcada por desconfianças, o que pode ser observado no caso "Lopes". Uma criança de 4 anos, chamada Érico Lopes, que morava em Matta de São João, Bahia, apresentou febre alta repentina, inquietação, dores indefinidas em diferentes partes do corpo. Ele foi levado a Salvador na tarde de 28 de janeiro de 1927 e, após examiná-lo, o Dr. Geister informou a Barros Barreto que era um caso de febre amarela. O paciente morreu no dia seguinte e uma autópsia parcial foi realizada com partes do fígado e do baço sendo preservadas. Enquanto aguardava o resultado do exame, Barros Barreto afirmou que recebeu uma carta de Clementino Fraga, Diretor do DNSP, relatando o caso "Lopes", dois dias antes da data que o próprio Barros Barreto pretendia informá-lo sobre a questấo.

O Secretário de Saúde e Assistência Pública da Bahia declarou que desconfiava que alguém ali tentava conseguir o seu emprego, mas deixava claro que, enquanto seu sogro fosse governador, isso não ocorreria. A antecipação de Fraga à informação levanta questionamentos sobre quem e quais os interesses envolvidos no compartilhamento do caso "Lopes" com membros do DNSP, no Rio de Janeiro.

${ }^{21}$ CONNOR para Russell (correspondência). RAC, RF records, IHB, RG 5, Series 1, FA 115, Box 293, Folder 3715. 15 ago. 1927.

${ }^{22}$ CONNOR, Michael Edward. Diary of the Yellow Fever Comission of Brazil by Dr. M. E. Connor, 1927. RAC, RF records, IHB, Division records, RG 5, Series 3, Subseries 3_305, FA 115, Box 127, Folder 1522, 1927, p. 36. 


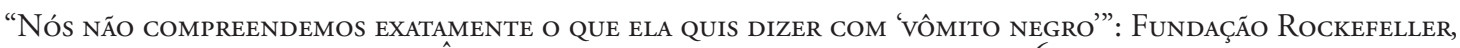
CIÊNCIA E A EPIDEMIA DE FEBRE AMARELA DE I 926

Connor seguiu para o Maranhão, onde o chefe da Profilaxia Rural, Cássio Miranda, que foi companheiro de Antônio de Barros Barreto na turma de 1913 do Curso de Aplicação do Instituto Oswaldo Cruz (IOC) (BATISTA, 2019a), se comprometeu a proibir o uso de barris na cidade, visto que o sistema de água estava disponível em todo o ambiente urbano e os barris eram possíveis criadouros de mosquitos. Dali, seguiu para Juazeiro (do Norte, Ceará). Ele chegou durante os dias de carnaval e a praça estava cheia de visitantes que foram participar das festividades.

Algumas daquelas pessoas tinham ido à procura do Padre Cícero, um dos líderes dos movimentos messiânicos na Primeira República brasileira (1889-1930). O padre, que atestou ter presenciado um "milagre", tinha sido expulso da igreja por não se retratar. Isso ocorreu em um momento em que a Igreja Católica vivenciava um processo internacional de reação ao avanço de correntes ideológicas e políticas heterodoxas, denominado "romanização", o Nordeste passava por estiagem e mantinha relações de trabalho nominalmente livres, mas sob o regime de agregados (que incluía lealdade armada em caso de disputas entre os patrôes, alguns deles coronéis). Mesmo assim, o padre passou a atrair um grande número de romeiros que acreditavam que ele fosse um santo ou um milagreiro (HERMANN, 2017, p. 123-138).

Depois de jantar, Connor e Smith fizeram uma visita ao religioso. Quando se aproximaram de sua casa, foram obrigados a escolher um lugar entre as inúmeras pessoas reunidas do lado de fora, na calçada e na rua, alguns deles suplicando de joelhos a sua ajuda. Após entrar na casa e alguns minutos de espera, foram recebidos. Ao ver Smith, Padre Cícero o abraçou e disse que estava feliz em vê-lo novamente no Ceará, pois temia que tivesse sido enviado para combater a febre amarela na África. Também deu as boas-vindas a Connor como representante da Fundação Rockefeller e teria feito "os maiores elogios à realização do nosso serviço em Joazeiro e esperava que continuássemos a trabalhar aqui”. ${ }^{23}$

Connor ficou muito interessado no tratamento recomendado pelo padre às pessoas que o procuravam em situação de doença e, para a sua satisfação, ouviu que não havia casos de febre amarela em Juazeiro há muitos anos:

Achei-o muito interessante ao relatar o tratamento dispensado às pessoas que insistiam em que ele lhes desse a sua bênção e conselho para combater doenças.

Ele afirma que recomenda fortemente que as pessoas com febre façam uma purgação e bebam toda a água que puderem. Se eles estão vomitando na hora, ele sugere um emético para limpar (adoçar) o estômago e depois começar o tratamento com água. Ele tem o cuidado de explicar que o povo foi informado repetidas vezes de que ele não foi dotado de nenhum poder divino para curá-los de suas enfermidades.

\footnotetext{
${ }^{23}$ Ibidem, p. 62. No original: "the highest praise of the accomplishment by our service in Joazeiro and hoped that we would continue, to work here" (tradução do autor).
} 


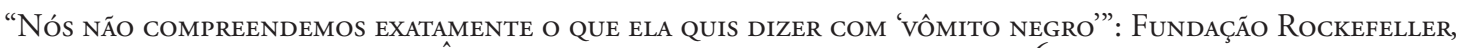
CIÊNCIA E A EPIDEMIA DE FEBRE AMARELA DE I 926

Ricardo dos Santos Batista

O padre disse-nos que até onde sabe a febre amarela não está presente em Joazeiro há anos. Os bebês continuam morrendo, diz ele, porque muitos são mal alimentados e negligenciados. Ele afirma agora haver vômito negro e tem certeza de que nâo é nesta cidade. Devemos voltar para ver o Padre segunda-feira. ${ }^{24}$

Além de um ícone religioso, Padre Cícero, que naquele momento tinha 85 anos, também possuía grande experiência, tornando-se figura política decisiva no quadro político do Ceará, do Vale do Cariri e de todo o Nordeste durante a Primeira República (HERMANN, 2017, p. 132). Em 1911, tornou-se o primeiro prefeito de Juazeiro (do Norte), elevado à categoria de município depois de acirrada disputa política com o Crato. Além disso, aliou-se com coronéis de outras vilas e foi fiador do pacto dos coronéis, de 1911, com a assinatura de um documento no qual se comprometiam a acabar com hostilidades recíprocas, não dar proteção a cangaceiros, não abrigar criminosos foragidos e se unirem em solidariedade ao então chefe oligárquico do Ceará, Antônio Pinto Nogueira Accioly. Se admitisse a existência da febre naquela localidade, ele tinha ciência dos possíveis impactos sobre a economia e sobre a própria peregrinação de fiéis para Juazeiro à sua procura.

Um dos objetivos de Connor era transferir o controle da amarílica para os chefes da Profilaxia Rural no Norte. Em 4 de março de 1927, Barros Barreto se reuniu com Henry, Kerr e Connor e concordou em assumir, a partir de $1^{\circ}$ de janeiro de 1928, as medidas de controle dos mosquitos em Salvador, mas, também, levar os serviços da Fundação Rockefeller para as cidades do interior, especialmente para as estações em Cachoeira, Nazaré e Santo Amaro. O diretor da Rockefeller indicava que a agência internacional poderia continuar a realizar medidas intensivas contra o Aedes aegypti até julho de 1928 e atuar com um pessoal reduzido até o final de 1927, desde que essa situação não contribuísse para eventos desfavoráveis. Além disso, ofereceu cooperação para o serviço do interior com o treinamento de guardas sobre como supervisionar o trabalho no campo e outras recomendaçóes ${ }^{25}$. Concernente a outros estados:

\footnotetext{
${ }^{24}$ Idem. No original: "I found him very interesting as he related his treatment of the people who insisting that he gave them his blessing and advise to combat illness.

He states that he strongly recommends that those with fever take a purge and drink all the water they can. If they are vomiting at the time come to him he suggest an emetic to clean (sweeten) the stomach after which They can begin the water treatment. He is careful to explain that the people have been informed time and again that he is not endowed with or by any divine power to cure them of their ailments. His is liberal with his funds to the poor.

The Padre told us as far as he knows yellow fever has not been presente in Joazeiro for Yyars past. The babies continue to die he says, because many are underfeed and neglected. He claims to now vomito preto [black vomit] and is certain that is not in this city. We are to return to see the Padre Monday" (tradução do autor). ${ }^{25}$ CONNOR para Sir (correspondência). RAC, RF records, IHB, RG 5, Series 1, FA 115, Box 293, Folder 3714. 25 mar. 1927.
} 


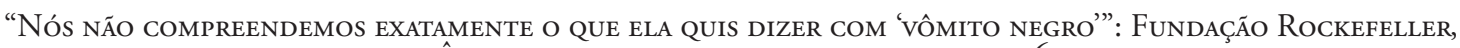
CIÊNCIA E A EPIDEMIA DE FEBRE AMARELA DE I 926

Ricardo dos Santos Batista

Meus planos atuais para esta área Norte do Brasil, i. e. Ceará, Maranhão e Rio Grande do Norte é ter a supervisão do Dr. L. C. Smith. Acho que depois que nossa campanha intensiva for encerrada ou entregue à Profilaxia Rural devemos manter uma 'estação de escuta' em Fortaleza e Smith será o homem para isso. Ele acompanharia os movimentos das estatísticas vitais, visitaria hospitais, consultaria médicos e faria visitas aos centros importantes. ${ }^{26}$

Entre o desejo de entregar o controle da febre amarela aos chefes do saneamento rural e as medidas tomadas para manter os baixos índices larvais, Connor viajava e, em seu diário, registrava muitas localidades em que parecia não haver amarílica, além de se posicionar criticamente contra o diagnóstico positivo em casos suspeitos.

Embora a epidemia de 1928 e a inoculação do macaco rhesus tenham sido tomadas como marcos decisivos para transformaçôes na história da febre amarela no mundo, com a queda de modelos animais, de teorias etiológicas vigentes e de novas técnicas aplicáveis ao trabalho de laboratório e de campo, como apontou Benchimol (2001, p. 125), é preciso ressaltar o papel da epidemia de 1926 no questionamento das concepçóes válidas até aquele momento e na orientação do trabalho do staff da agência internacional. Mesmo que se tentasse manter válida a teoria dos focos-chave, o evento epidêmico continuou influenciando açôes e estratégias a serem tomadas, inclusive os lugares que Connor escolheu para visitar, diretamente relacionados ao evento de 1926. Connor, Smith, a teoria dos focos-chave e a ciência promovidas pela Fundação Rockefeller continuavam à sombra da epidemia.

Apenas dois anos após o "ressurgimento" da amarílica, uma nova instituição chegou a Salvador com o intuito de encontrar outros rumos para o conhecimento científico: o laboratório da febre amarela. Em seguida, em 1930, Connor foi substituído por Fred Soper na liderança da Campanha da Febre Amarela e reorganizou o serviço com ênfase no processo de viscerotomia e testes de promoção em camundongos (BENCHIMOL et al, 2001, p. 125).

\section{A criação do Laboratório da Febre Amarela}

O médico escolhido para dirigir o Laboratório da Febre Amarela em Salvador foi Nelson Caryl Davis (1892-1933). Desde cedo interessado em doenças tropicais, atuou nas Filipinas

${ }^{26}$ CONNOR, Michael Edward. Diary of the Yellow Fever Comission of Brazil by Dr. M. E. Connor, 1927. RAC, RF records, IHB, Division records, RG 5, Series 3, Subseries 3_305, FA 115, Box 127, Folder 1522, 1927, p. 57. No original: "My present plans for this Northern area of Brasil, i. e. Ceará, Maranhão and Rio Grande do Norte is to have the supervision come under Doctor L. C. Smith. I feel that after our intensive campaign has been brought to a close or turned over to the Prophylaxia Rural we should maintain a 'listening station' inFortaleza and Smith will be the man for this. He would keep track of the movements of vital statistics, visit hospitals, confer with physicians and make visits to the important centers" (tradução do autor). 


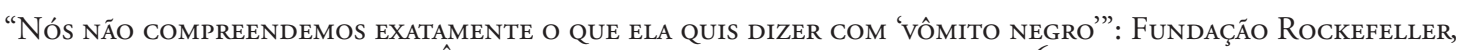
CIÊNCIA E A EPIDEMIA DE FEBRE AMARELA DE I 926

entre 1910 e 1912 e, depois de formado em medicina, integrou o staff da Rockefeller (19221933), investigando ancilostomíase e malária na América do Sul. Entre julho de 1922 e dezembro de 1923, atuou como diretor estadual do IHB no Rio Grande do Sul (KORNDÖRFER, 2013, p. 187). Em 1924, trabalhou com o médico brasileiro Waldemar Rocha, na Ilha dos Marinheiros, no mesmo estado, em ações contra a ancilostomíase, que resultaram em uma pesquisa que criticava o uso do óleo de chenopódio nas campanhas de controle da enfermidade dirigidas pela agência internacional (MAGALHÁES, 2016, p. 356). E, em 1927, fez parte de uma missão financiada pela Rockefeller à Argentina, com o objetivo de colaborar com o governo no saneamento, controle de mosquitos e tratamentos de enfermos. Nessa ocasião, Davis trabalhou com o entomologista Raymond Corbett Shannon (CURTO et al, 2013, p. 107-108), que mais tarde também o acompanhou no laboratório da Bahia e, posteriormente, atuou no controle da malária no Rio Grande do Norte (cf. LOPES, 2020).

Em 7 de julho de 1928, Davis e Johannes Bauer desembarcaram no porto de Salvador, vindos do Rio de Janeiro, no navio Itaquera. Eles foram recebidos pelos médicos Eduardo Araújo, Michael Connor e A. W. Burke. No mesmo dia, visitaram as instalaçóes do edifício que lhes foi oferecido, em Monte Serrat, e aceito por Davis ${ }^{27}$. A presença de Bauer na Bahia é indicativa da importância da instituição que seria inaugurada. Em 1927, ele trabalhou no Laboratório de Acra, na Costa do Ouro, e, junto com Adrian Stokes e Paul N. Hudson, desenvolveu pesquisas na tentativa de domesticar o agente etiológico da febre amarela. Os animais de laboratório usuais (ratos, cães, gatos, camundongos) se mostraram refratários à febre amarela africana, mas os cientistas conseguiram inocular experimentalmente o macaco rhesus com o sangue de um africano chamado Asibi, que sobreviveu ao ataque da doença. Em poucos meses eles confirmaram que a febre amarela era causada por um vírus ultramicroscópico e filtrável, capaz de ser transmitido entre macacos e que poderia ser transportado pelo mosquito Aedes aegypti (BENCHIMOL et al, 2001, p. 215; MAGALHÁES, 2016, p. 78).

O periódico soteropolitano $A$ Tarde noticiou a chegada dos pesquisadores em uma matéria intitulada "Acompanhando a peste nos macacos". Davis informou a pequena pausa realizada no Rio de Janeiro, vindos de Nova Iorque. Disse que Henrique Aragão trabalhava no IOC daquela cidade e, que, possivelmente ainda em 1928, apresentaria estudos novos sobre a amarílica. Além disso:

O objectivo da nossa vinda ao seu paiz é da fundação de um laboratorio serumtherapeutico, onde continuarei com a inoculação do virus da febre amarela, os meus estudos em torno desta moléstia.

Depois da fundação deste laboratorio, que se dará, dentro de algumas semanas, em um pavilhão de Monte Serrat, que nos foi, gentilmente offerecido, pelo Dr. Barros Barreto, o Dr.

\footnotetext{
${ }^{27}$ DAVIS, Nelson Caryl. Bahia Laboratory Diary, v. 1, 1928-1931. RAC, RF records, projects, RG 1.1, Series 300 Latin America - Series 833 Lebanon (FA 386b). Box 42, Folder 247. 23 out. 1928.
} 
“Nós NÃo COMPREENDEMOS EXATAMENTE O QUE ELA QUIS DIZER COM 'VÔMITO NEGRO””: FUNDAÇÃo RocKEFELLER, CIÊNCIA E A EPIDEMIA DE FEBRE AMARELA DE I 926

Ricardo dos Santos Batista

Bauer regressará á New York.

$[\ldots]$

Com a inoculação do vírus nos macacos, onde, aliás, o quadro clinico não se assemelha muito, ao do homem, embora o seja idêntico no anatomo-pathologico, mantemos aquele mesmo objectivo de pé [encontrar um soro imunizador para a febre amarela] (destaque do original) ${ }^{28}$.

A criação do laboratório da febre amarela mostrava a necessidade de um maior conhecimento sobre a doença após a epidemia de 1926. Em Salvador, era motivo de prestígio para Antônio de Barros Barreto, que poderia apresentar à sociedade baiana o trabalho desenvolvido pela agência que o financiou para estudar no exterior e com a qual mantinha estreitas relações. Mas isso não significava a ausência de suspeitas mútuas, ou mesmo conflitos explícitos.

Davis e Bauer não confiavam completamente na atuação do Secretário de Saúde e Assistência Pública. Após a instalação completa do laboratório, eles receberam a visita do governador, em 18 de setembro de 1928. Mas, dias depois, Davis se queixava do empenho de Barros Barreto para viabilizar o desenvolvimento das atividades, como, por exemplo, a aquisição de novos animais para inoculação:

Parece que teremos problemas na saída dos macacos que chegam no "Antônio Delfino" amanhã. Duvido que Dr. Barros Barreto esteja cooperando como deveria, porque quando o governador visitou o laboratório, ele disse ao Dr. Barros Barreto, em minha presença, para dar os passos necessários para fazer nossos animais passarem. ${ }^{29}$

Por outro lado, após a reconfiguração do acordo da Fundação Rockefeller com a União, em 1929, Barros Barreto, que esperava assumir o controle da febre amarela na Bahia, ameaçou retirar o seu apoio à agência internacional. Naquele momento, havia o desejo de que o estado baiano fosse utilizado como uma escola de treinamento para médicos brasileiros nomeados como futuros diretores de estações da amarílica pelo serviço de saúde pública ${ }^{30}$. Clementino Fraga, no entanto, explicitou a Connor que a Fundação Rockefeller deveria assumir todo o Serviço de Febre Amarela e que Barros Barreto cuidaria exclusivamente dos

\footnotetext{
${ }^{28}$ ACOMPANHANDO A peste nos macacos. A Tarde, Salvador, 12. jul. 1928. p. 1.

${ }^{29}$ DAVIS, Nelson Caryl. Bahia Laboratory Diary, v. 1, 1928-1931. RAC, RF records, projects, RG 1.1, Series 300 Latin America - Series 833 Lebanon (FA 386b). Box 42, Folder 247. 23 out. 1928. No original: "Its looks like we may gave trouble getting out the monkeys that arrived on the 'Antonio Delfino' tomorrow. I doubt that Dr. Barros Barreto is co-operating as he should, because When the governor visited the laboratory he told Dr. Barros Barreto in my presence to take the necessary steps in getting our animals through" (tradução do autor). ${ }^{30}$ CONNOR, Michael Edward. Diary of the yellow fever comission of Brazil by Dr. M. E. Connor. January 1 - 1928 - October 24, 1928. RAC, RF records, projects, SG 1.1, Series 300, Latin America, Series 833 Leabnon (FA 386b). Series 305: Brazil, Subseries 305.O, Box 40, Folder 232, 1928; CONNOR, Michael Edward. Diary of the Yellow Fever Comission of Brazil. 1929-1930. RF records, projects, SG 1.1, Series 300, Latin America - Series 833 Lebanon (FA 386b). Box 40, Folder 233, 1929, p. 2.
} 
“Nós NÂO COMPREENDEMOS EXATAMENTE O QUE ELA QUIS DIZER COM 'VÔMITO NEGRO””: FUNDAÇÃO ROCKEFELLER, CIÊNCIA E A EPIDEMIA DE FEBRE AMARELA DE I 926

Ricardo dos Santos Batista

trabalhos de isolamento e de tratamento dos casos. Esse posicionamento se deu, possivelmente, devido a uma hostilidade de Barros Barreto para com Fraga e pela "ameaça” de tentar a separação da Fundação Rockefeller do controle da febre amarela na Bahia. Para Connor:

Pelo presente acordo ele perde o prestígio na Bahia, por não ter sido nomeado chefe do serviço local de febre amarela. Ele está ansioso que tentemos remediar isso. Estou igualmente ansioso para que o assunto seja resolvido de maneira satisfatória. Ele também deseja ter um orçamento para fumigação etc, se essas medidas forem por eles praticadas. Ele não tem fé nelas, mas a Faculdade de Medicina sim e, portanto, devem fazer parte da campanha profilática da febre amarela. ${ }^{31}$

Embora houvesse um interesse, por parte dos brasileiros, na realização das atividades da Fundaçáo Rockefeller para o controle da febre amarela na Bahia, esse processo foi marcado por conflitos que envolveram agentes das diferentes nacionalidades. Inclusive, o aceite para a realização da fumigação é indício de uma negociação, já que a teoria dos focos-chave da Fundação Rockefeller caía por terra e a fumigação, que ainda era considerada uma medida eficaz entre outros médicos baianos e repudiada pela Rockefeller, foi autorizada.

Em meio a esses conflitos, temidos como prejudiciais à atuação da agência filantrópica, o laboratório mantinha uma rotina constante de inoculação em animais, especialmente em macacos. Trocas de conhecimento aconteciam pela interação de diferentes profissionais, entre eles Davis, Bauer e Eduardo Araújo. ${ }^{32} \mathrm{O}$ diário de Michael Connor informa sobre diferentes momentos em que os médicos brasileiros, especialmente Barros Barreto e Araújo, estavam interessados em ouvir sobre o trabalho desenvolvido por Bauer na África ${ }^{33}$.

Ao longo de 1929, o laboratório funcionou como um direcionador das açôes de controle da febre amarela. Por meio da investigação experimental, orientava sobre quais caminhos deveriam ser seguidos, em quais frentes deveria ser reforçada ou reduzida a atuação da IHD. Uma das descobertas significativas foi a identificação de que a espécie Aedes scapullaris poderia ser um vetor eficiente do vírus da febre amarela. A seção entomológica fez pesquisas com mosquitos, de forma ágil, e desenvolveu um programa para realizar

\footnotetext{
${ }^{31}$ CONNOR, Michael Edward. Report Yellow Fever Service, Northern Brazil, 1929. RF records, Photographs, Series 100-100 (FA 003) 305: Brazil, FA 003, Box 69, Folder 1453. 26 fev. 1930; CONNOR, Michael Edward. Diary of the Yellow Fever Comission of Brazil. 1929-1930. RF records, projects, SG 1.1, Series 300, Latin America - Series 833 Lebanon (FA 386b). Box 40, Folder 233, 1929, p. 10. No original: "Under the presente agreement he loses prestigie in Bahia for not having been named chefe of the local yellow fever service. He is anxious that we try to remedy this. I am equally anxious to have the matter adjusted to his satisfaction. He also wishes to have a budget for fumigation etc., if these measures are to be practiced by him. He does not have faith in them but the medical faculty does and therefore They are to be part of the prohilatic campaign against yellow fever" (tradução do autor).

${ }^{32}$ Eduardo Araújo foi bolsista da Fundação Rockefeller e, a partir de 1927, dirigiu o IOC-Ba.

${ }^{33}$ CONNOR, Michael Edward. Diary of the yellow fever comission of Brazil by Dr. M. E. Connor. January $1-$ 1928 - October 24, 1928. RAC, RF records, projects, SG 1.1, Series 300, Latin America, Series 833 Leabnon (FA 386b). Series 305: Brazil, Subseries 305.O, Box 40, Folder 232, 1928, p. 126.
} 


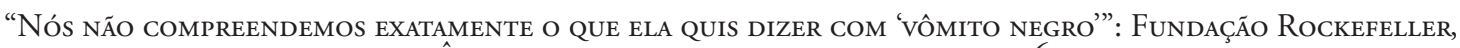
CIÊNCIA E A EPIDEMIA DE FEBRE AMARELA DE I 926

estudos semelhantes em outras áreas. Foram realizadas pesquisas preliminares, mas continuadas o suficiente para orientar as investigaçôes.

Entre as primeiras percepçôes, Davis compreendeu que havia, sob certas condiçôes intensivas, a criação de stegomya em recipientes na superfície do solo a uma distância média de 150 pés das habitaçóes humanas; e, de forma relativa, pouco stegomya presente nas plantas, enquanto os bambus poderiam se tornar locais preferenciais para os insetos, mais especialmente perto das habitaçôes. Além disso, o serviço mais imediato e com maior êxito da entomologia foi a confirmaçáo da necessidade de estender as medidas para o controle de stegomya "extra-mural" (fora dos muros das residências), e, ao mesmo tempo, enfrentar o problema do scapullaris.

Até aquele momento, os esforços de controle da febre amarela estavam concentrados na redução da reprodução dentro de casa, mas constatou-se que, durante os meses da chuva, a criação extramuros era mais importante. Começava com a primeira chuva torrencial e continuava por meses até algumas semanas após o encerramento da estação chuvosa, sendo que durante esse período as calhas dos telhados das casas ficavam infestadas ${ }^{34}$.

No primeiro semestre foi realizado trabalho intenso de exame das preparaçôes histológicas de casos fatais da amarílica e injeção de sangue nos macacos oriundos de pacientes que estavam no primeiro dia de febre. Além disso, foi feito o uso de soros convalescentes em testes de proteção. Grande parte do material que chegou ao laboratório veio do estado de Pernambuco, onde ocorreu uma série de pequenas epidemias a esse respeito. Segundo Porto (2020b, p. 356-257), na década de 1920, o laboratório do Recife ficava estrategicamente perto do porto e da estação central do trem, portas de entrada e saída de pessoas não imunes na região, o que também facilitava o deslocamento dos médicos pela Região Norte. A instituição atendia à intensa demanda das análises de casos suspeitos da cidade de Recife e do interior de Pernambuco e estados vizinhos, especialmente os casos duvidosos que os laboratórios da Paraíba do Norte, hoje Paraíba, Natal e Maceió não conseguiam responder satisfatoriamente, antes de ser inaugurado o laboratório de Salvador. A partir de 1928, essas instituiçôes estreitaram relaçôes para agilizar a confirmação de diferentes diagnósticos de febre amarela, que deveriam ocorrer em Salvador.

O laboratório da Fundação Rockefeller se ampliava e, ao fim de 1929, possuía uma secretária, um técnico microscopista, um motorista para o caminhão, um assistente chefe do laboratório entomológico, um ajudante em entomologia (encarregado de tabular as pupas, separar os mosquitos fêmeas emergentes), cinco ajudantes em entomologia (que traziam as coleçôes de fora, bambus, bromélias, outros focos designados e atuavam como ajudantes de Shannon nas viagens), um atendente especialmente encarregado de supervisionar a alimentação e medir a temperatura dos animais, um ajudante (que limpava a vidraria, lavava

\footnotetext{
${ }^{34}$ CONNOR, Michael Edward. Report Yellow Fever Service, Northern Brazil, 1929. RF records, Photographs, Series 100-100 (FA 003) 305: Brazil, FA 003, Box 69, Folder 1453. 26 fev. 1930.
} 


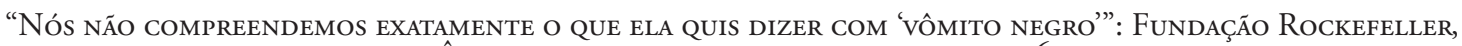
CIÊNCIA E A EPIDEMIA DE FEBRE AMARELA DE I926

\section{Ricardo dos Santos Batista}

o laboratório e esterilizava o material), cinco ajudantes (que limpavam as gaiolas, operavam o incinerador), além de um carpinteiro, um jardineiro e seus ajudantes (DAVIS, 1929, p. 5) (Figuras 4 e 5).

Figura 4: Laboratório da Fundação Rockefeller em Salvador

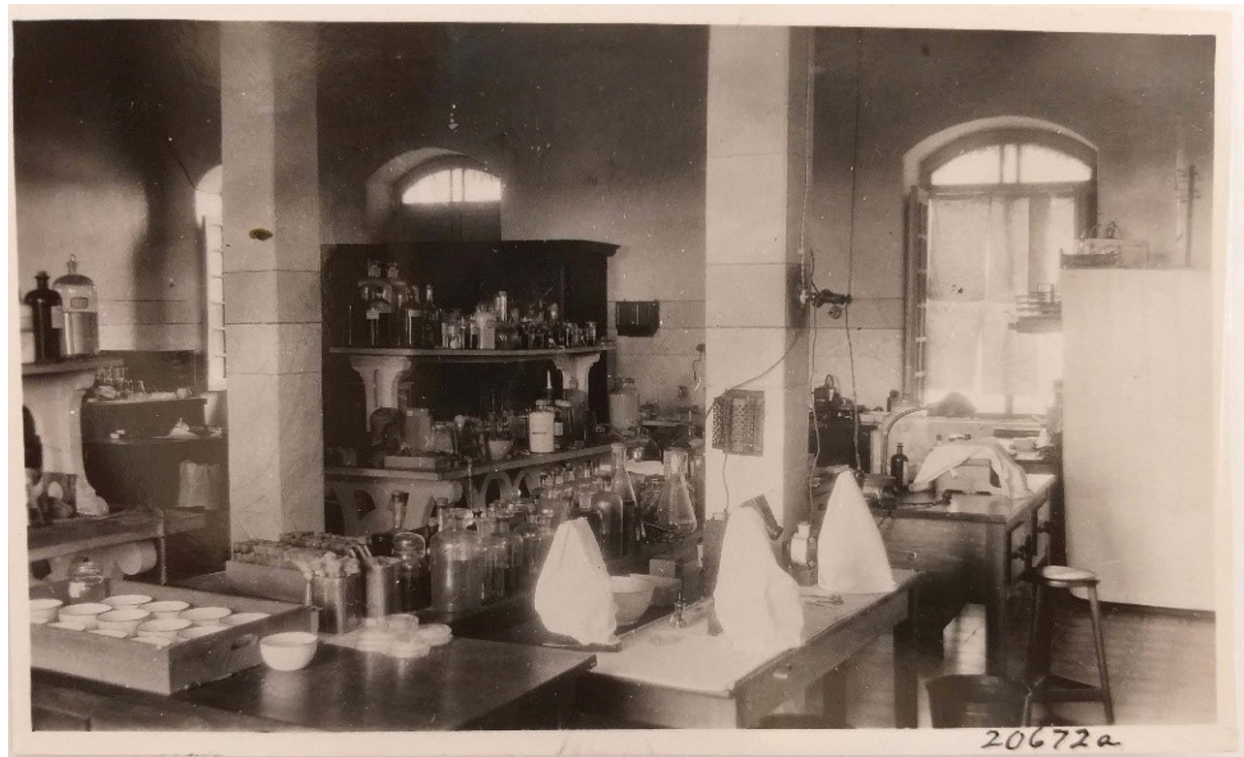

Fonte: RAC, RF records, photographs, series 100-1000, FA 003, Box 70, Folder 1520

Figura 5: Macaco inoculado no Laboratório da Fundação Rockefeller em Salvador

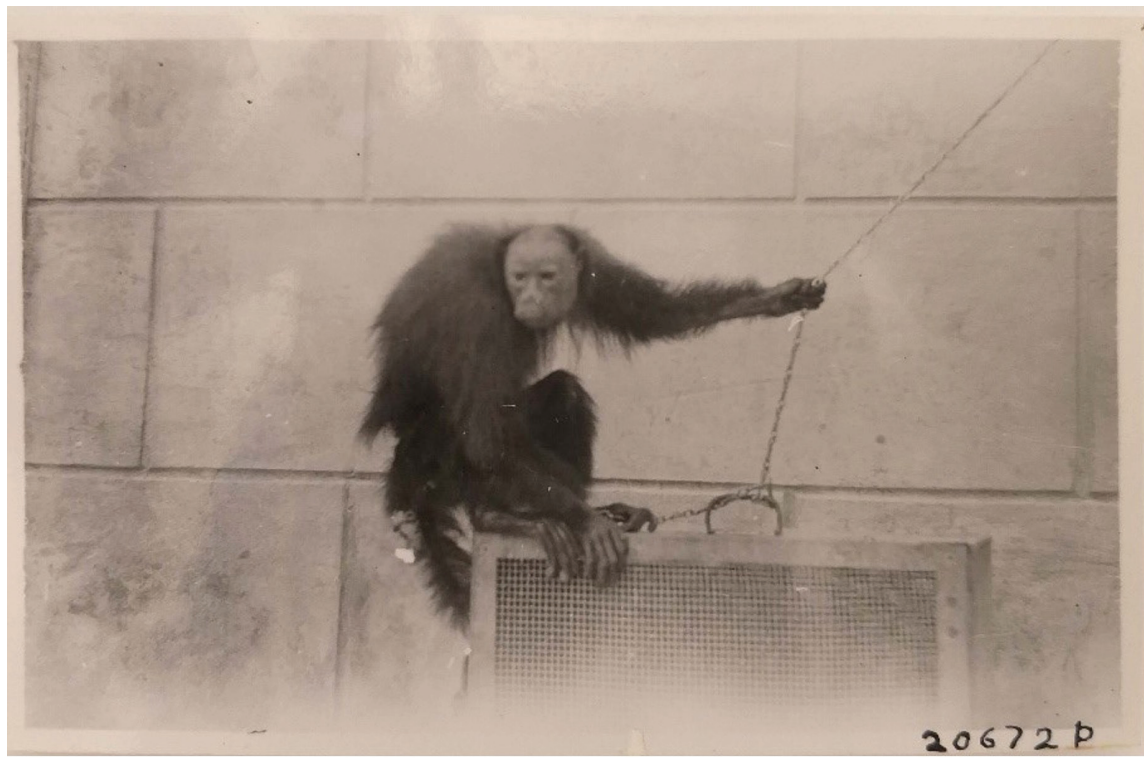

Fonte: RAC, RF records, photographs, series 100-1000, FA 003, Box 70, Folder 1520 


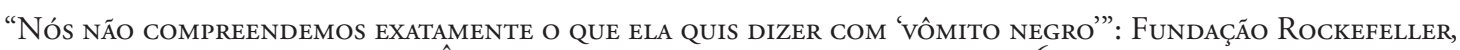
CIÊNCIA E A EPIDEMIA DE FEBRE AMARELA DE I926

Ricardo dos Santos Batista

\section{Considerações finais}

A análise da epidemia de 1926, e de seus desdobramentos, evidencia os conflitos políticos, sociais e científicos existentes nas relaçôes entre indivíduos de diferentes nacionalidades, presentes na saúde internacional. A irrupçáo da febre amarela colocou em questão conhecimentos até então considerados válidos e utilizados para o diagnóstico, conhecimentos até entâo empregados para a identificação da enfermidade como uma entidade específica, com uma forma também específica de disseminação e de erradicaçáo, o que envolvia agentes patológicos, meios de transmissão e métodos profiláticos.

Uma epidemia se define pelo seu caráter episódico, mas isso não quer dizer que suas consequências se esgotem no acontecimento. Pelo contrário, ao longo de 1927, muito se questionou se a amarílica era a responsável pelo adoecimento da população no ano anterior, a partir de diagnósticos realizados por membros do staff da Fundação Rockefeller, especialmente por Michael Connor. Além disso, o evento epidêmico contribuiu para que um laboratório fosse criado na cidade de Salvador. Nele, foram realizadas atividades que ajudaram a minar as bases da teoria dos focos-chave, que até entáo orientava a Campanha Mundial da Febre Amarela.

O Laboratório da Febre Amarela antecipou a tendência adotada pela Fundaçáo Rockefeller, a partir de 1930, de privilegiar a relaçáo entre o laboratório e o campo, com ênfase nesse último, após reconhecer que era necessário buscar mais informaçóes sobre aquela doença, para uma redefinição dos seus métodos de controle. Segundo Löwy, (2006, p. 170), as iniciativas para empreender novas pesquisas deveriam vir do campo e não mais do laboratório central. A partir de pesquisas realizadas no subúrbio de Salvador, mas também em municípios do Norte do estado, a exemplo de Senhor do Bonfim, pesquisadores do laboratório como Nelson Davis e Raymond Corbett Shannon, e médicos brasileiros como Serafim Júnior, investigaram diferentes tipos de mosquitos e analisaram, por exemplo, a possibilidade de que fossem transmissores da febre amarela.

A epidemia foi um evento que se contrapôs aos anseios de determinado grupo, notadamente os integrantes do staff da Fundaçâo Rockefeller e contribuiu para a reestruturação do conhecimento científico sobre a febre amarela em ampla esfera. Se a doença pode organizar e desorganizar sociedades, como já propuseram Jacques Revel e Jean Pierre Peter (1976), o caso aqui analisado é um exemplo interessante sobre como isso pode ocorrer, inclusive, em perspectiva global.

\section{Fontes documentais}

A FEBRE amarella está extincta: declaraçóes sensacionais do dr. White, chefe da Missão Rockefeller no Brasil. A Tarde, Salvador, 24 abr. 1925, p. 1. 


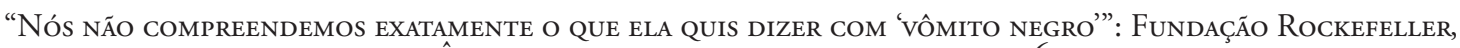
CIÊNCIA E A EPIDEMIA DE FEBRE AMARELA DE I 926

Ricardo dos Santos Batista

A RONDA dos epidêmicos. A Tarde, Salvador, 10 de jul. 1926, p. 1.

ACÇÃO DA Fundação Rockefeller no Ceará. Diário de Pernambuco, Recife, 13 mar. 1926, p. 1. ACOMPANHANDO A peste nos macacos. A Tarde, Salvador, 12. jul. 1928. p. 1.

COMITÉ DE Hygiene da Liga das Naçóes. Diário de Pernambuco, Recife, 29 maio 1926, p. 1. CONNOR para Russell (correspondência). RAC, RF records, IHB, RG 5, Series 1, FA 115, Box 293, Folder 3715. 15 ago. 1927.

CONNOR para Sir (correspondência). RAC, RF records, IHB, RG 5, Series 1, FA 115, Box 293, Folder 3714. 25 mar. 1927.

CONNOR, Michael Edward. Diary of the Yellow Fever Comission of Brazil. 1929-1930. RF records, projects, SG 1.1, Series 300, Latin America - Series 833 Lebanon (FA 386b). Box 40, Folder 233, 1929.

CONNOR, Michael Edward. Diary of the yellow fever comission of Brazil by Dr. M. E. Connor. January 1 - 1928 - October 24, 1928. RAC, RF records, projects, SG 1.1, Series 300, Latin America, Series 833 Leabnon (FA 386b). Series 305: Brazil, Subseries 305.O, Box 40, Folder 232, 1928.

CONNOR, Michael Edward. Diary of the Yellow Fever Comission of Brazil by Dr. M. E. Connor, 1927. RAC, RF records, IHB, Division records, RG 5, Series 3, Subseries 3_305, FA 115, Box 127, Folder 1522, 1927.

CONNOR, Michael Edward. Report Yellow Fever Service, Northern Brazil, 1929. RF records, Photographs, Series 100-100 (FA 003) 305: Brazil, FA 003, Box 69, Folder 1453. 26 fev. 1930.

CONTRA A febre amarella. Diário de Pernambuco, Recife, 29 maio 1926, p. 1.

DAVIS, Nelson Caryl. Bahia Laboratory Diary, vol 1, 1928-1931. RAC, RF records, projects, RG 1.1, Series 300 Latin America - Series 833 Lebanon (FA 386b). Box 42, Folder 247. 23 out. 1928.

DAVIS, Nelson Caryl. Narrative report for the year 1929 - Yellow fever laboratory, Bahia, Brazil. RAC, RF records, IHB, Division records, RG 5, Series 3, FA 115, Box 128, Folder $1525,1929$.

FEBRE AMARELLA. Diário de Pernambuco, Recife, $1^{\circ}$ jul. 1926, p. 7.

FREIRE para Carr (correspondência). RAC, RF records, IHB, Division records, RG 5, Series 3, FA 115, Box 127, Folder 1522. 10 abr. 1926.

MARQUES para Barros Barreto (correspondência). RAC, RF records, RG 5, Series 3, Subséries 3_305, FA 115, Box 127, Folder 1522. 23 jul. 1926.

O MOSQUITO traz a febre e a morte. Diário de Pernambuco, Recife, 15 set. 1926, p. 7. RAC, RF records, IHB, Division records, RG 5, Series 3, FA 115, Box 114, Folder 1454. 


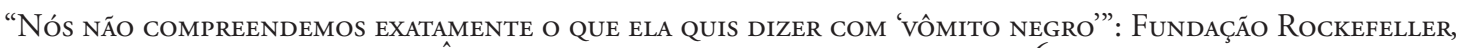
CIÊNCIA E A EPIDEMIA DE FEBRE AMARELA DE I 926

RAC, RF records, photographs, series 100-1000, FA 003, Box 70, Folder 1520.

ROCKEFELLER FOUNDATION. RAC. Report of yellow fever outbreak Brazil, 1926. RF records, IHB, Division records, RG 5, Series 3, FA 115, Box 114, Folder 1454. 26 ago. 1926.

SCANNELL, E. J. Summary of yellow fever situation in Brazil Jan. to Aug., 1926 by E. J. Scannell. RAC, RF records, IHB, Division records, RG 5, Series 3, FA 115, Box 114, Folder 1454. 5 ago. 1926.

TEREMOS FEBRE amarela em Alagoinhas? A Tarde, Salvador, 4 maio 1926, p. 1.

\section{Referências}

BATISTA, Ricardo dos Santos. A formação inicial de Antônio Luis Cavalcanti de Albuquerque de Barros Barreto: uma trajetória rumo à saúde internacional. História, Ciências, Saúde Manguinhos (Rio de Janeiro), v. 26, n. 3, p. 801-822, jul-set. 2019a.

BATISTA, Ricardo dos Santos. De Baltimore às "Lavras Diamantinas": internacionalização/ interiorização da saúde na Bahia (1920-1930). Tempo, Niterói, v. 26, n. 2, p. 430-453, maio-ago., 2020.

BATISTA, Ricardo dos Santos. Educação e propaganda sanitárias: desdobramentos da formação de um sanitarista brasileiro na Fundação Rockefeller. História, Ciências, Saúde Manguinhos (Rio de Janeiro), v. 26, n. 4, p. 1189-1202, out.-dez. 2019b.

BATISTA, Ricardo dos Santos; SILVA, Maria Elisa Lemos Nunes da. A atuação de Antônio Luis Cavalcanti e Albuquerque de Barros Barreto na Reforma Sanitária da Bahia (19241930).

BATISTA, Ricardo dos Santos; SOUZA, Christiane Maria Cruz de. O curso da epidemia: a Fundação Rockefeller e os surtos de febre amarela na Bahia em 1926. Outros Tempos (São Luiz), v. 17, n. 30, p. 219-243, jul.-dez. 2020.

BENCHIMOL, Jaime Larry et al. Cerejeiras e cafezais: relaçôes médico-científicas entre Brasil e Japão e a saga de Hideyo Noguchi. Rio de Janeiro: Bom Texto, 2009.

BENCHIMOL, Jaime Larry. Febre amarela: a doença e a vacina, uma história inacabada. 20. ed. Rio de Janeiro: Editora Fiocruz/Bio-Manguinhos, 2001.

BERTUCCI, Liane Maria. Influenza: a medicina enferma. Campinas: Editora da Unicamp, 2004.

BIRN, Anne-Emanuelle. Marriage of convenience: Rockefeller International Health and revolutionary Mexico. University of Rochester Press, 2006.

CUETO, Marcos. The cycles of erradication: the Rockefeller Foundation and Latin 


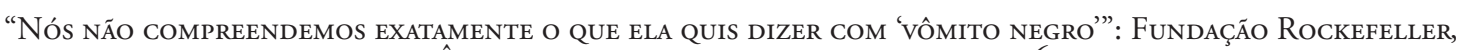
CIÊNCIA E A EPIDEMIA DE FEBRE AMARELA DE I 926

American Public Health 1918-1940. In: WEINDLING, Paul (edit.). International Health organizations and movements 1918-1939. Cambridge: Cambridge University Press, 1995.

CURTO, Susana et al. Historia del control del paludismo en Argentina. Bol. Acad. Nac. Med. B. Aires, n. 91, v. 1, p. 77-93, jan.-jun, 2013.

FARLEY, John. To cast out disease: a history of the International Health Division of the Rockefeller Foundation (1915-1951). Oxford: Oxford University Press, 2004.

HERMANN, Jacqueline. Religião e política no alvorecer da República: os movimentos de Juazeiro, Canudos e Contestado. In: FERREIRA, Jorge; DELGADO, Lucila de Almeida Neves. O Brasil republicano: o tempo do liberalismo excludente. 9. ed. Rio de Janeiro: Civilização Brasileira, 2017.

KORNDÖRFER, Ana Paula. “An international problem of serious proportions”: a cooperação entre a fundação Rockefeller e o Governo do Estado do Rio Grande do Sul no Combate à ancilostomíase e seus desdobramentos (1919-1929). Tese (Doutorado em História) Pontifícia Universidade Católica do Rio Grande do Sul. Porto Alegre, 2013.

LOPES, Gabriel. Anopheles gambiae no Brasil: antecedentes para um "alastramento silencioso", 1930-1932. História, Ciências, Saúde-Manguinhos, Rio de Janeiro, v. 26, n. 3, p. 823-839, 2019.

LÖWY, Ilana. Virus, mosquitos e modernidade: a febre amarela no Brasil entre ciência e política. Rio de Janeiro: Editora Fiocruz, 2006.

MAGALHÃES, Rodrigo Cesar da Silva. A erradicação do Aedes Aegypti: febre amarela, Fred Soper e saúde pública nas Américas (1918-1968). Rio de Janeiro: Editora Fiocruz, 2016.

PORTO, Paloma. A higiene como missão: Fundação Rockefeller, filantropia e controvérsia científica - Paraíba do Norte (1923-1930). João Pessoa: Editora do CCTA/UFPB, 2020a.

PORTO, Paloma. Regimes de prova: a presença do laboratório no combate à febre amarela no Nordeste brasileiro (1916-1930). In: BATISTA, Ricardo dos Santos; SOUZA, Christiane Maria Cruz de; SILVA, Maria Elisa Lemos Nunes da. Quando a História encontra a Saúde. São Paulo: Hucitec, 2020b.

REVEL, Jacques; PETER, Jean-Pierre. O corpo: o homem doente e sua história. In: LE GOFF, Jacques; NORA, Pierre. História: novos objetos. Rio de Janeiro: Francisco Alves, 1976.

ROSENBERG, Charles. What is an epidemic? AIDS in historical perspective. Daedalus, Cambridge, v. 118, n. 2, p. 1-17, 1989.

ROSENBERG, Charles. The Tyranny of Diagnosis: specific entities and individual experience. In: The. Milbank Quaterly, v. 80, n. 2, p. 237-260, 2002.

SOARES JÚNIOR, Azemar. “O doente parecia mordido de cobra, de 'bicha venenosa': anotaçôes sobre a febre amarela. Revista Territórios e Fronteiras, Cuiabá, v. 13, n. 1, jan.-jul., 2020. 


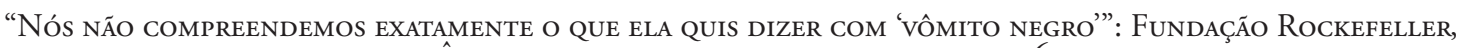
CIÊNCIA E A EPIDEMIA DE FEBRE AMARELA DE I926

\section{Ricardo dos Santos Batista}

WILLIAMS, Steven C. Nationalism and Public Health: the convergence of Rockefeller Foundation Technique and brazilian federal authority during the time of yellow fever, 19251930. In: CUETO, Marcos. (edit.). Missionaries of Science: The Rockefeller Foundation and Latin America. Bloomington: Indiana University Press, 1994. 